\title{
RETRACTED ARTICLE: Inverse Method for Simultaneous Determination of Soil Water Flux and Thermal Properties with a Penta-Needle Heat Pulse Probe
}

\author{
Changbing Yang • Gerard Kluitenberg · Scott B. Jones
}

Received: 23 February 2010 / Accepted: 12 July 2010 / Published online: 24 July 2010

(C) Springer Science+Business Media B.V. 2010

This article has been published Online First, but is withdrawn due to the fact that the script was submitted and the article was published without the co-authors being informed.

C. Yang $(\bowtie)$

Bureau of Economic Geology, The University of Texas at Austin, Austin, TX 78758, USA

e-mail: yangcb@gmail.com

G. Kluitenberg

Department of Agronomy, Kansas State University, Manhattan, KS 66506, USA

S. B. Jones

Department of Plants, Soils, and Climate, Utah State University, Logan, UT 84322, USA 